\title{
SENAYAN WATERLAKE SPORT ISLAND
}

\author{
Felicia Lim ${ }^{1)}$, Martin Halim²) \\ 1)Program Studi S1 Arsitektur, Fakultas Teknik, Universitas Tarumanagara, ifelicialim@gmail.com \\ 2) Program Studi S1 Arsitektur, Fakultas Teknik, Universitas Tarumanagara, martinhalim90@gmail.com
}

Masuk: 10-01-2020, revisi: 28-01-2020, diterima untuk diterbitkan: 09-05-2020 (doi: 10.24912/stupa.v2i1.6779)

\begin{abstract}
Abstrak
Berdasarkan hasil Reset Kesehatan Dasar tahun 2018, masalah kesehatan di Indonesia dibagi menjadi dua macam yaitu penyakit menular dan penyakit tidak menular. Penyakit menular sudah mengalami banyak penurunan yang cukup signifikan sedangkan untuk penyakit tidak menular justru masih mengalami kenaikan. Banyak cara yang dapat dilakukan untuk menjaga tubuh tetap sehat terhindar dari penyakit. Menerapkan pola hidup yang Sehat untuk kesehatan jasmani, ketenangan rohani juga dibutuhkan untuk kesehatan mental para masyarakat khususnya untuk daerah yang memiliki kepadatan serta mobilitas tinggi seperti di Jakarta ini. Waterlake Sport adalah jenis olahraga fisik yang berhubungan dengan air khususnya danau. Island sendiri berarti pulau. Senayan Waterlake Sport Island berlokasi di dekat Gelora Bung Karno (GBK), pusat olahraga terbesar di Jakarta bahkan di Indonesia yang menyediakan lebih dari 18 jenis olahraga di dalamny. Metode perancangan yang digunakan adalah pattern language dengan mengkaji pola fisik di sekitar tapak dan membuat pola baru dengan mengaitkan program bangunan yang dihasilkan. Island yang berarti sebuah pulau merupakan tempat dari area Waterlake Sport itu sendiri. Selain olahraga air sebagai program utama, ada juga program utama lainnya yaitu Kuliner Sehat dan Pasar Apung. Kuliner sehat yang dimaksud adalah Kedua program ini bertujuan menyediakan suatu area tempat makan dengan konsep sehat sekaligus sebagai edukasi untuk masyarakat yang masih menganggap bahwa pola makan sehat diartikan dengan sesuatu yang membosankan dan tidak enak bahwa menjadi sehat tidak haruslah menderita.
\end{abstract}

Kata kunci: kuliner sehat; pasar terapung; sehat; waterlake

\begin{abstract}
Based on the results of the Basic Health Reset in 2018, health problems in Indonesia are divided into two types namely infectious and non-communicable diseases. Infectious diseases have experienced many significant decreases whereas for non-communicable diseases it is still experiencing an increase. Many ways you can do to keep the body healthy from disease. Applying a healthy lifestyle for physical health, spiritual calm is also needed for the mental health of the community, especially for areas that have high density and mobility like in Jakarta. It is undeniable that these factors are often the main triggers of mental health problems in today's society. Waterlake Sport is a type of physical sport related to water, especially lakes. Senayan Waterlake Sport Island is located near Gelora Bung Karno (GBK), the largest sports center in Jakarta and even in Indonesia which provides more than 18 types of sports in it. The design method used is pattern language by examining the physical patterns around the site and creating new patterns by linking the resulting building programs. Besides water sports as the main program, there are also other main programs, namely Healthy Culinary and Floating Market. Both of these programs aim to provide a dining area with a healthy concept as well as education for people who still think that a healthy eating pattern is defined as something boring and unpleasant that being healthy does not have to suffer.
\end{abstract}

\section{Keywords: health; waterlake sport; healthy culinary; floating market}




\section{PENDAHULUAN}

Kota merupakan salah satu tempat tinggal dimana kehidupan manusia berlangsung yang dapat dikatakan paling kompleks, karena perkembangannya amat dipengaruhi oleh aktivitas pengguna perkotaan yang menyesuaikan dengan perkembangan zaman dan tuntutan hidup. Kota juga memperngaruhi kehidupan segala bidang yang berdampak pada timbulnya masalah-masalah yang kompleks dimana masalah tersebut memerlukan pemecahan masalah.

Dari 4 masalah bawaan tersebut, kesehatan menjadi pokok masalah yang penting dimana menurut hasil Riset Kesehatan Dasar (Riskesdas) Kementrian Kesehatan pada tahun 2018 kemarin, menujukan bahwa sebagian besar masalah kesehatan yang paling sering terjadi di Jakarta yang dikelompokan menjadi 4 kelompok besar yaitu masalah gizi, penyakit menular, penyakit tidak menular dan penyakit mental. Hanya masalah penyakit menular seperti ISPA menjadi $4.4 \%$ dari $13 \%$, Malaria menjadi $0,4 \%$ dari $1,4 \%$ dan Diare menjadi $12,3 \%$ dari $18,5 \%$ dan masalah gizi seperti Stunting menjadi $30,8 \%$ dari $37,2 \%$ dan Gizi buruk menajdi $17,6 \%$ dari $19,6 \%$ yang mengalami penurunan signifikan. Untuk masalah penyakit tidak menular seperti Kanker yang bertambah sebanyak $1,8 \%$ dari $1,2 \%$, Stroke sebesar $7 \%$ dari $1,4 \%$, Gangguan ginjal kronis sebesar 3,8\% dari $2 \%$, Diabetes sebesar 8,5\% dari 6,9\% dan Hipertensi sebanyak 34,1\% dari 25,8\% pada tahun 2013 lalu. Sedangkan untuk penyakit mental mengalami kenaikan yang cukup drastis yaitu sebanyak $7 \%$ dari $1,3 \%$.

Gangguan mental yang dimaksud ini juga dikenal dengan istrilah stress dimana stress adalah gangguan atau kekacauan mental dan emosional yang disebabkan oleh faktor luar atau ketegangan. Stress dapat dibagi menjadi 2 macam yaitu:

a. Eustress: Hasil dari respon terhadap stress yang bersifat sehat, positif dan konstruktif (membangun).

b. Distress: Hasil dari respon terhadap stress yang bersifat tidak sehat, negative dan destruktif (merusak).

Situasi dan tekanan yang dapat menyebabkan stress dikenal dengan istilah stressor. Pada umumnya, masyarakat berpikir tentang stress sebagai negative seperti jadwal kerja yang padat dan melelahkan atau konflik dengan rekan. Stress yang tinggi dapat membuat seseorang menjadi lelah, sakit dan bahkan tidak mampu untuk berkonsentrasi atau berpikir jernih. Stress yang sudah terlampau berat inilah yang akhirnya menyebabkan gangguan mental.

\section{KAJIAN LITERATUR}

\section{Rekreasi}

Menurut kamus bahasa Inggris, kata rekreasi merupakan terjemahan dari bahasa Inggris yang berasal dari kata benda recreation yang berarti hal penciptaan kembali, hal bersuka ria dan hal melepas lelah. Dari pengertian dasar rekreasi di atas, dapat disimpulkan bahwa unsur-unsur penting dalam perumusan rekreasi adalah sebagai berikut:

- Penyegaran fisik dan mental

- Penyegaran daya kreasi kembali

- Kegiatan yang dilakukan secara sukarela dan oleh semua orang baik secara perorangan maupun kelompok

- Kegiatan yang memberikan kegembiraan bagi pelaku

- Kegiatan yang dilakukan pada/untuk memafaatkan waktu luang secara konstruktif

Jadi, rekreasi adalah suatu kegiatan yang dilakukan oleh kelompok atau perorangan dengan sukarela, dalam memanfaatkan waktu luang secara kondusif untuk memulikan kesegaran fisik serta daya kreasi. 


\section{Olahraga}

Olahraga merenggangkan ketegangan pada otot-otot seperti yang dikatakan dalam buku "Bersahabat dengan Stress" oleh Mahsun. Olahraga membakar zat-zat beracun yang merugikan tubuh dan mengahasilkan zat-zat yang menghilangkan rasa sakit. Olahraga membuat seseorang merasa gembira, menyegarkan tubuh dan menurunkan ketegangan. Dengan demikian olahraga mengurangi dampak stress.

\section{Olahraga air}

Menurut buku pengetahuan olahraga untuk SLA dan sederajat, Olahraga air adalah olahraga yang dilakukan di air atau yang medannya berupa air (waduk, sungai, danau, laut dan sebagainya). Berdasarkan luasnya medan, olahraga air dapat dibagi menjadi:

a. Olahraga perairan luas yaitu olahraga layar, mendayung, canoeing, power boat, dragon boat, ski air, surfing dan selam.

b. Olahraga perairan terbatas yaitu renang, polo air, loncat indah dan senam air. Sedangkan berdasarkan sifatnya, olahraga air dapat dikelompokan menjadi :

a. Olahraga air prestasi yaitu olahraga air yang bertujuan membina kegiatan olahraga jenis tertentu secara intensif dan tekun untuk memperoleh tingkat kemahiran dan prestasi yang semakin tinggi

b. Olahraga rekreasi adalah olahraga yang bertujuan mengajak berbagai kalangan masyarakat untuk melakukan olahraga kegemarannya masing-masing agar memperoleh rasa senang dan sehat jasmani dan rohani, kepuasan sosial serta pemulihan kesegaran jasmani.

Dalam buku "Rules of The Game", cabang olahraga air dapat meliputi:
a. Renang
b. Layar
c. Dayung
d. Power boating
e. Ski air

\section{Waterfront}

Berdasarkan fungsinya, waterfront dapat dibedakan menjadi 7 jenis yaitu:

a. Cultural Waterfront

Cultural waterfront mewadahi aktivitas budaya, pendidikan dan ilmu pengetahuan. Hal ini dapat dilihat dari beberapa fasilitas yang ada pada kawasan waterfront tersebut sepertu aquarium, memorial fountain, waterfront dengan program/event khusus.

b. Environmental Waterfront

Environmental Waterfront yaitu pengembangan waterfront yang bertumpu pada usaha peningkatan kualitas lingkungan yang mengalami degradasi, memanfaatkan pontensi dan keaslian lingkungan yang tumbuh secara alami. Kegiatan yang dapat dilakukan adalah berjalanjalan menikmati keaslian alam, rekreasi dan taman bermain.

c. Historical Waterfront

Historical waterfront pada umumnya berkembang sebagai upaya konservasi dan restorasi bangunan bersejarah di kawasan tepi air. Konteks kesejarahan yang dapat dikembangkan dapat berupa dermaga tua seperti di Baltimore, Maryland dan Boston, Museum Kapal seperti di Galvastone, Texas, bedungan dan jembatan kuno seperti di Pennsylvania, bangunan tua di New Orlens, jalur transportsi tua sepanjang perairan Seattle dan Washington.

\section{d. Mixed Used Waterfront}

Adalah waterfront yang merupakan kombinasi dari perumahan, perkantoran restoran, pasar rumah sakit dan/atau tempat-tempat kebudayaan 


\section{e. Recretional Waterfront}

Pengembangan waterfront dengan fungsi aktivitas rekreasi dapat didukung dengan berbagai fasilitas antara lain: taman bermain, taman air, taman duduk, taman hiburan, area memancing ,riverwalk, amphitheater, diving, pelabuhan, gardu pandang, fasilitas perkapalan, pavilion, fasilitas olahraga, marina, museum, hotel, restoran dan aquarium.

\section{f. Residental Waterfront}

Pengembangan waterfront dengan fungsi utama sebagai perumahan. Fasilitas yang dibangun berupa kampung nelayan, apartemen, town house, flat, row, rumah pantai, villa rekreasi dan kesehatan.

\section{g. Working Waterfont}

Kawasan waterfront yang menampilkan sisi kelautan. Aktivitas yang diwadahi umumnya berhubungan dengan perikanan, penangkapan, penyimpanan dan pengolahan. Aktivitas pembuatan kapal dan terminal angkutan air merupakan ciri utama waterfront ini.

\section{Relaksasi}

Relaksasi merupakan suatu kegiatan untuk memfokuskan dan menenangkan pikiran dan "latihan olah tubuh" sebagai bagian untuk melatih tubuh agar tetap segar dan bugar dalam menghadapi berbahai macam masalah kesehatan salah satunya adalah penyakit stress. Macam-macam relaksasi yang diminati masyarakat saat ini antara lain:

\section{a. Meditation}

Berbagai teknik dapat digunakan selama meditasi; kesemuanya menimbulkan fokusnya pikiran terhadap sebuah objek atau aktivitas dan mengabaikan gangguan. Meditasi telah ditunjukan untuk menggantikan respon stress "bertarung dan menghindar" dan hal ini dilakukan sebagai pencerahan spiritual oleh masyarakat timur dan bagi masyarakat barat digunakan tanpa adanya hubungan ndengan konteks religius untuk memerangi kondisi stress. (Woodham, Anne.,\&Peters, David.(1997)

b. Pijat

Lukisan bangsa mesir memperlihatkan orang di pijat dan pada naskah bangsa China serta India menunjukan kegunaan dalam merawat penyakit pada keadaan darurat. Para ahli Romawi dan yunani menilai bahwa pijat merupakan cara utama untuk menghilangkan rasa sakit : Julius Caesar di pijat setiap harinya untuk menghilangkan neuralgia (Woodham, Anne.,\&Peters, David.(1997)) Hippocrates, bapak pengobatan dunia, menulis pada abad ke 5 sebelum masehi, "the physician must be experienced in many things but assuredly in rubbing.... for rubbing can bind a joint that is too loose and loosen a joint that is too rigid" (Woodham, Anne.,\&Peters, David.(1997). Encyclopedia of complementary medicine)

Prinsip dasarnya adalah semua bentuk sentuhan dirasakan melalui sentuhan kulit yang merupakan organ sensor tubuh terbesar. Pijatan lembut atau belaian dapat melepas endorphin, pembunuh rasa sakit alami tubuh serta memberikan perasaan nyaman serta dan sehat. Pijatan dapat menenangkan seseorang yang sebenarnya secara langsung memberi efek terhadap sistem tubuh yang mengatur detak jantung, tekanan darah, pernafasan dan pencernaan. Meskipun tidak menangani sebuah permasalahn secara langsung, perasaan sehat yang dihasilkan dari pijatan dapat menurunkan jumlah peredaran hormone stress pada tubuh seperti kortisol dan norepineohrine yang melemahkan sistem kekebalan tubuh. (Woodham, Anne.,\&Peters, David.(1997))

c. Hidroterapi (spa)

Bangsa yunani kuno percaya bahwa air mengandung zat-zat kehidupan dan rahasia kesembuhan. Dalam hidroterapi, air digunakan untuk pengobatan luar maupun dalam - panas dan dingin, 
sbagai cairan, uap atau es untuk membersihkan, revitalisasi, mengembalikan dan menjaga kesehatan. Secara tradisional, hidroterapi terdiri dari mandi, sauna dan kompres. Tetapi, pada zaman modern ini telah diperkenalkan whirlpool dan water jets. (Woodham, Anne.,\&Peters, David.(1997))

\section{Architecture Third Place}

"Architecture as a third place" atau disebut juga sebagai ruang ketiga merupakan ruang ketiga yang diperuntukan untuk relaksasi sekaligus sebagai tempat untuk bersosialisasi dengan masyarakat lainnya sebagai bentuk "pelarian" dari tempat pertama yang biasa kita sebut rumah dan juga tempat kedua yang kita kenal sebagai tempat kerja. "Third place" adalah tempat yang bersifat netral, sebagai tempat alternative, siapapun dapat menggunakannya sebagai tempat aktivitas dan dapat digunakan oleh kalangan manapun. "Third place" dapat ditemukan di mana - mana dan memiliki bentuk yang berbagai macam sesuai dengan kehidupan dan budaya masyarakat sekitarnya. Masyarakat cenderung sungkan untuk melakukan interaksi dengan orang sekitar.

Bisa dibilang masyarakat Los Angeles sungkan untuk meninggalkan tempat "perlindungan" mereka dikarenakan waktu dan berkendara untuk jangka waktu yang lama merupakan faktor utama pendukung hal tersebut. Berbeda untuk daerah Vienna dimana masyarakat senang untuk diajak mengunjungi "Hall" konser yang mudah dicapai dengan berjalan kaki saja. Tak hanya "Hall" konser, gedung opera, gedung bioskop dan beberapa restoran dan kafe menjadi tempat masyarakat untuk bertemu teman lama bahkan kadang pertemuan yang tidak terencana bisa terjadi di tempat tempat yang baru saja disebutkan. Daerah Los Angeles mempunyai ratusan kali lebih banyak tempat tinggal tetapi juga memberikan banyak kesan bahwa masyarakat di sana tidak menikmati keberadaan mereka di tempat tesebut.

\section{METODE}

\section{Pattern Languange}

Bahasa Pola atau Pattern Language adalah metode perancangan yang digunakan didalam proyek ini. Pattern Language pertama kali diperkenal oleh Christopher Alexander yang kemudian diterbitkan dalam buku "A Pattern Language: Towns, Buildings, Construction (1977)". Didalam bukunya, Alexander menjelaskan pola dari berbagai bentukan fisik mulai dari tata ruang kota, peletakan ruang komunal, rumah, hingga detail dari tiap-tiap ruang. Ada sekitar 253 pola yang dijelaskan seperti cara pengaplikasian dan cara penyusunannya beserta turunan dari masalah tersebut dan bagaimana pola tersebut dapat digunakan. Di sisi lain, Alexander menjelaskan bahwa Pattern Language adalah cara untuk berbagi pengetahuan tentang bangunan didalam kehidupan masyarakat. Konsep lokal dan pola dengan kebudayaan spesifik juga bisa ditemukan di dalam karyanya.

Pola-pola yang ada didalam buku ini adalah hasil pembelajaran Christopher Alexander beserta rekannya sehingga kegunaannya adalah bukan untuk secara literal dicontoh atau digunakan kedalam bangunan tetapi lebih kepada acuan cara berfikir untuk memberikan sebuah solusi terhadap sebuah masalah dengan menggunakan pola.

\section{Metode Survey Lapangan}

Survey dilakukan di sekitar lokasi tapak dengan mengkaji fenomena-fenomena yang ada didalamnya. Survey dimulai dengan pendataan secara visual elemen-elemen pembentuk ruang kota secara fisik dan aktivitas warga di sekitar tapak dan pendatang. Tapak berada di sebelah kawasan Gelora Bung Karno. Gelanggang Olahraga (Gelora) Bung Karno adalah sebuah kompleks olahraga serbaguna di Senayan, Jakarta, Indonesia. Kompleks olahraga ini menjadi rumah bagi stadion utama, 
stadion sekunder, lapangan sepak bola, stadion air, stadion tenis (indoor dan outdoor), lapangan hoki, bisbol dan panahan, serta beberapa gimnasium dalam ruangan. Terlihat di bagian selatan tapak, tapak berbatasan langsung dengan jalan Gerbang Pemuda. Sedangkan untuk bagian timur tapak berbatasan langsung dengan jalan Gatot Subroto. Terlihat juga pedestrian sudah tersedia dengan baik yaitu dengan lebar $2 \mathrm{~m}$. Selain kawasan GBK, tapak juga berhubungan langsung dengan Pulau Dua restoran yang buka setiap harinya mulai dari jam 10 pagi hingga jam 10 malam. Restoran ini termasuk dalam kategori restoran menengah keatas dilihat berdasarkan range harga pada restoran tersebut.
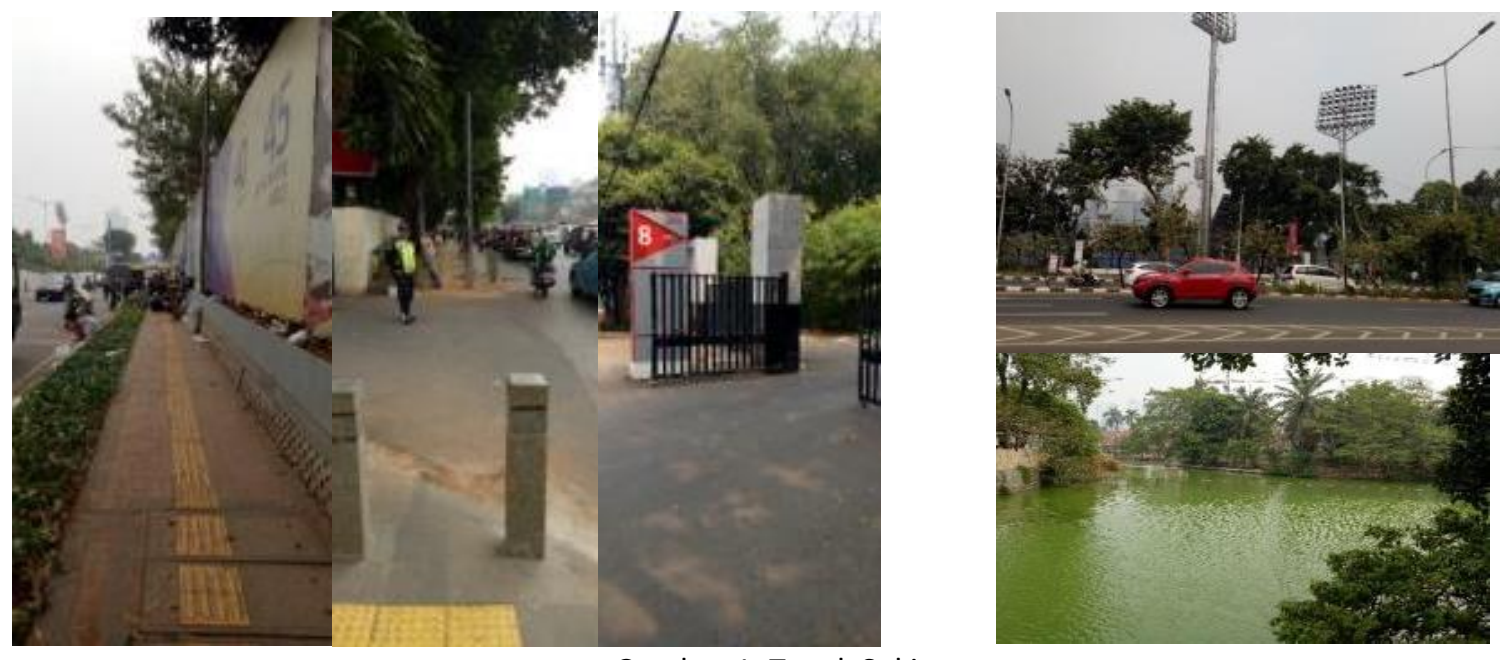

Gambar 1. Tapak Sekitar

Sumber: Penulis, 2019

\section{DISKUSI DAN HASIL}

Dari survey lapangan data-data diolah dikelompokan berdasarkan dengan subjek yang berkaitan. Data-data kemudian dianalisa dan digunakan untuk menjadi acuan awal mendesign. Data-data Hasil analisa tapak ditranslasikan menjadi proses desain sebagai berikut:
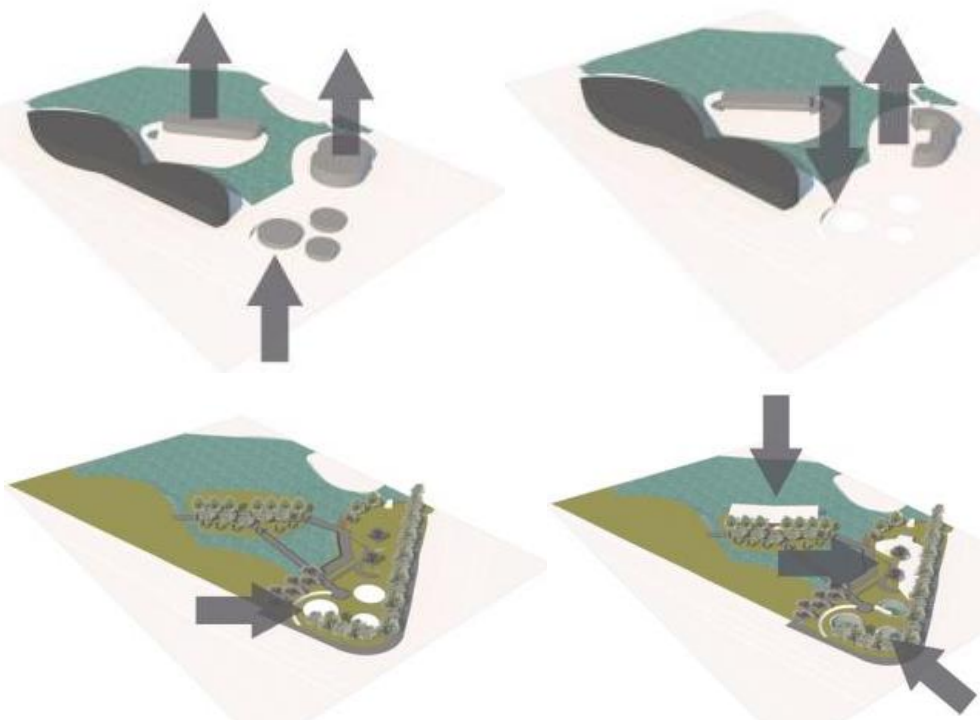

Gambar 2. Design Scheme

Sumber: Penulis, 2019 
Penempatan massa bangunan. Mengangkat bidang yang terbentuk berdasarkan GSB setinggi peraturan KB dari tata kota DKI Jakarta. Kemudian mengangkat sebagian massa bangunan untuk tujuan view ke "pulau" serta memasukan massa bangunan ke daam tanah untuk tujuan privasi. Setelah itu, diberikan void juga untuk bangunan di dalam tanah agar bangunan tetap mendapatkan cahaya matahari secara alami. Lanscape penghijauan dan perkerasan mengikuti massa dan bentuk site bangunan dan yang terakhir adalah penempatan bangunan utama terdapat pada bagian "pulau" sehingga bagian massa bangunan lainnya berorientasi terhadap bangunan utama tersebut.

Dari hasil analisa didapatkan gubahan akhir yang telah melewati serangkaian proses berdasarkan data survey tapak. Gubahan kemudian dilanjutkan kedalam proses desain selanjutnya. Yaitu memasukan ruang-ruang berdasarkan organisasi ruang yang didapatkan dari hasil metode Pattern Language. Dari pola baru yang telah terbentuk, organisasi ruang dimasukan kedalam gubahan disesuaikan dengan kebutuhan ruang dan konsep bangunan secara keseluruhan. Penyusunan ruang dilakukan secara vertical dan horizontal tergantung dengan besarnya kaitan antar ruang satu sama lain. Gubahan akhir yang didapat dijadikan acuan namun tidak menutup kemungkinan adanya perubahan-perubahan yang dilakukakan selama proses desain. Didapati hasil akhir sebagai berikut, organisasi ruang yang telah diorganisasi berdasarkan hasil dari pattern language dan dimasukan kedalam gubahan masa hasil dari survey lapangan yang telah melewati serangkaian proses gubahan.

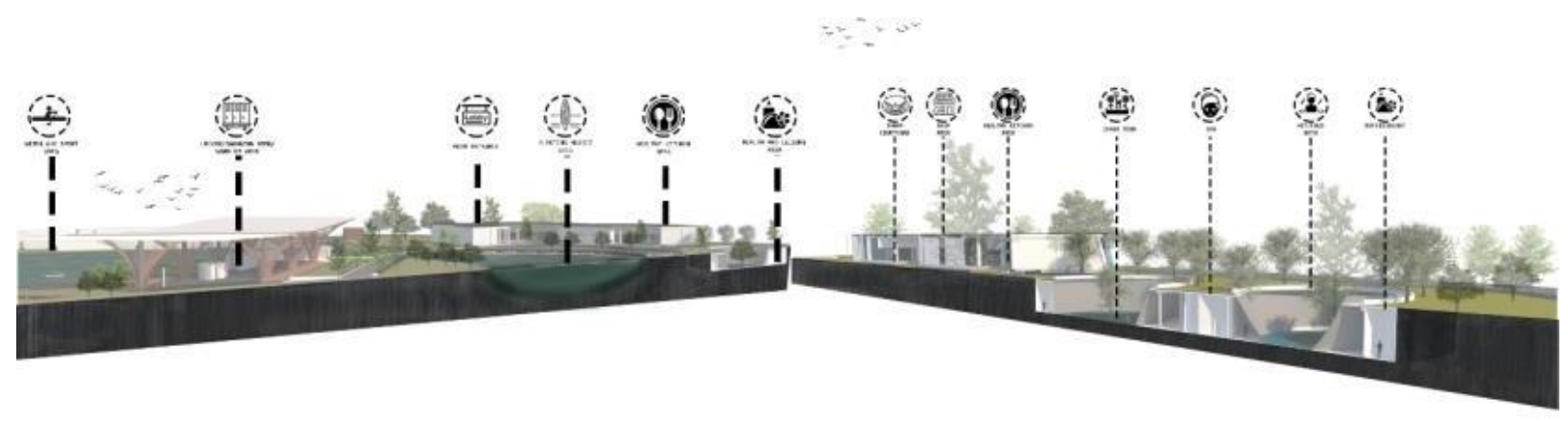

Gambar 3. Potongan Tapak

Sumber: Penulis, 2019 


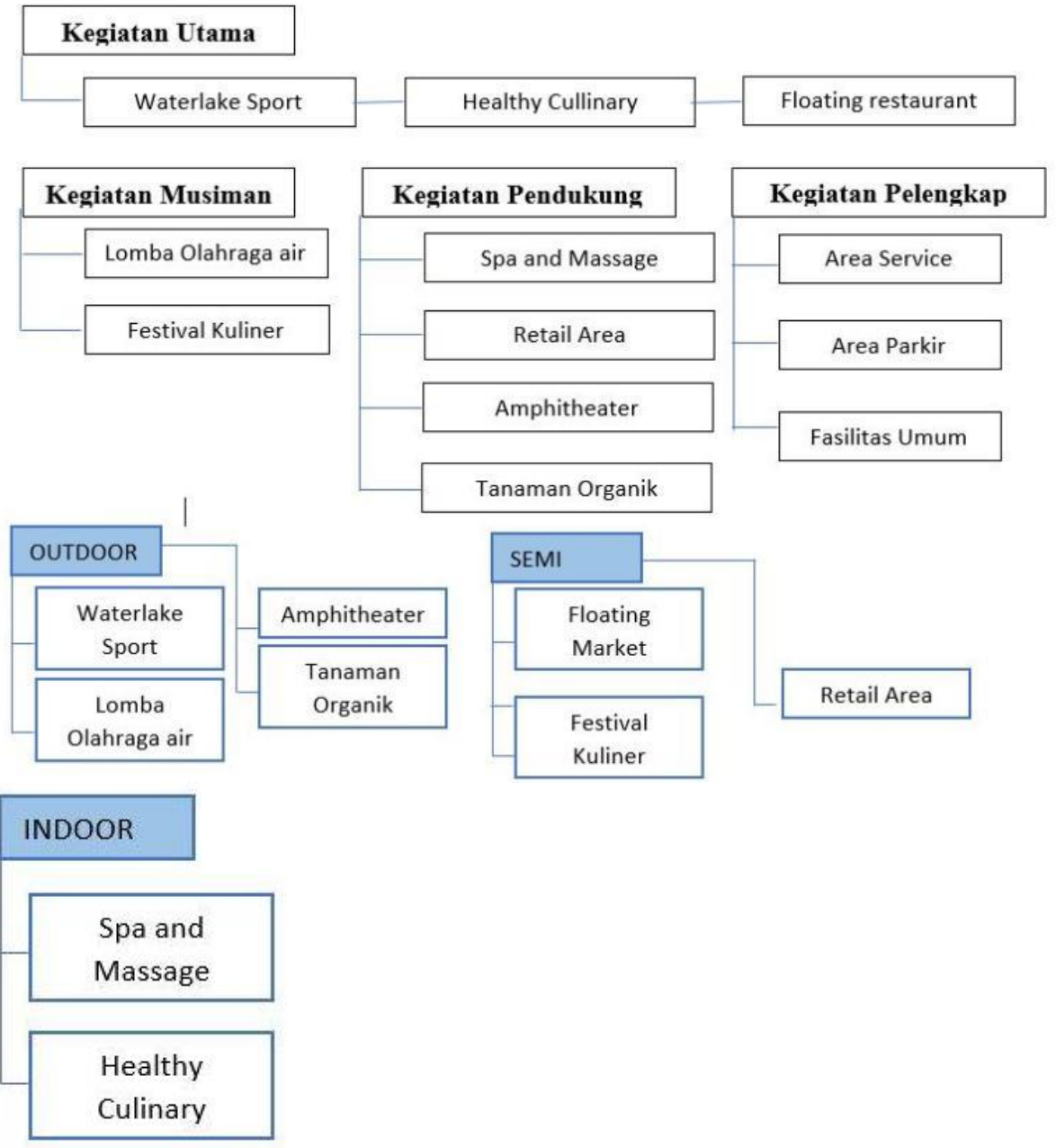

Gambar 4. Program Ruang

Sumber: Penulis, 2019

Program bangunan dikelompokan menjadi tiga kelompok utama yakni, Waterlake Sport, Health Culinary dan Floating Restaurant. Waterlake sport memiliki fasilitas yang berhubungan langsung dengan olahraga air yaitu Canoe dan Paddle Boarding. Health Culinary dimaksudkan untuk menjawab masalah kesehatan masyarakat. Dengan adanya program tersebut diharapkan dapat membantu mengatasi masalah tersebut dengan cara adanya penghitungan berat gizi dari makanan yang nantinya akan disajikan sehingga masyarakat bisa menghitung dengan sendirinya kebutuhan gizi yang diperlukan. Selain makanan sehat dan bergizi , rasa maupun presentasi dari masakan pada program ini juga di perhatikan untuk merubah persepsi kepada masyarakat bahawa makan sehat bukan berarti makanan yang tidak tidak enak untuk dimakan.

Program Healthy Culinary ini berada di semi indoor dan out door. Semi indoor dimana massa bangunan bebas ac namun tetap memperhatikan juga sirkulasi udara yang terjadi di dalamnya sehingga udara bisa mengalir dengan baik. Hal ini juga di lakukan untuk mengurangi penggunaan ac untuk mengurangi efek pemanasan global. Untuk bagian outdoor disediakan healthy culinary bagian floating market dimana pengunjung bisa menikmati makanan sehat dengan konsep pasar terapung dengan tujuan memudahkan masyarakat agar tidak perlu berjauh - jauh mengunjungi daerah Bandung, Bogor, maupun Sentul untuk menikmati suasana pasar terapung. 

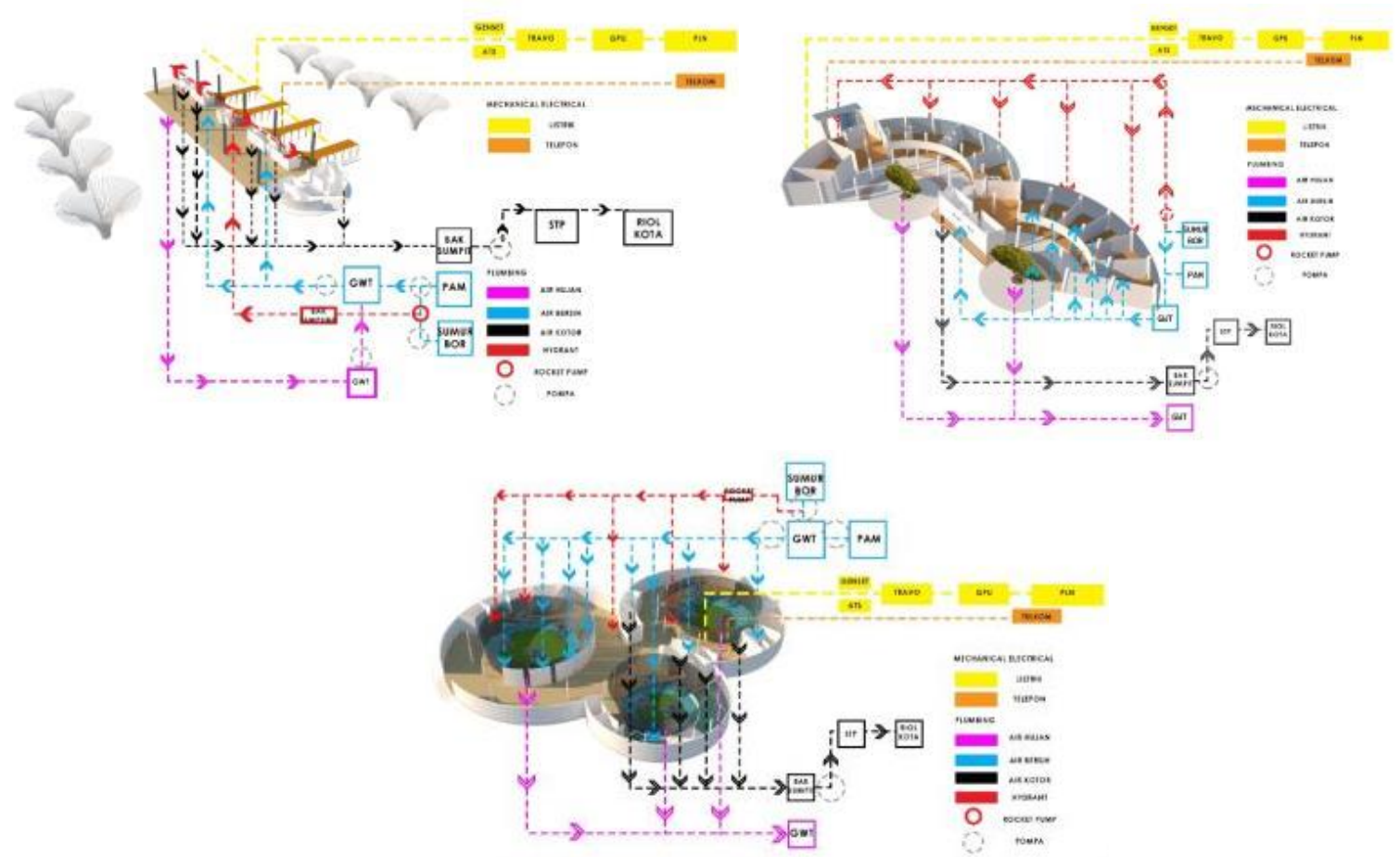

Gambar 5. Exploded \& MEP Plan

Sumber: Penulis, 2019

Yang paling terakhir adalah bagian penunjang bangungan yaitu area health and leisure. Area Health and leisure berada di lantai basement. Hal ini dilakukan untuk mengatasi kebutuhan ruang tanpa melanggar batas kdb yang telah di tentukan maka dari itu area ini di buat kedalam tanah. Pada area ini, terdapat spa room, massage area dan refleksiologi serta kolam permandian air panas dan dingin. Program ini dibuat untuk menjawab masalah kesehatan tidak menular yaitu masalah penyakit mental. Meskipun sudah mengalami penurunan yang signifikan, program ini tetap di hadirkan agar bisa lebih menekan lagi angka tersebut kedepannya. Karena salah satu kunci kesehatan mental adalah dengan menjaga suasana hati dan pikiran agar tetap terkontrol. Terlebih lagi, masyakarat kota jakarta merupakan masyarakat dengan mobilitas serta kepadatan jadawal yang tinggi. Selain itu juga, penempatan bangunan di bawah tanah seperti ini dilakukan dengan tujuan memaksimalkan kebutuhan ruang privasi namun tidak lupa bahwa cahaya matahari juga dibutuhkan pada bangunan. Maka dari itu bangunan di buat bukaan untuk tujuan masuknya pencahayaan alami pada bangunan sehingga bisa menekan penggunan pecahayaan buatan (lampu listrik).

Dari hasil pengorganisasian ruang proses desain dilanjutkan dengan pengolahan denah dengan melakukan serangkaian studi ergonometri dan studi kasus dari proyek-proyek yang berhubungan. Melihat dari sasaran pengguna bangunan (user) yang adalah milenial pengolahan denah dibuat lebih menarik dan dinamis, bercermin dari karakteristik generasi milenial. Konsep desain mengambil inspirasi dari teori Proxemics oleh Edward T. Hall. Dalam teorinya Hall mengatakan bahwa manusia memiliki personal space yang diilustrasikan dengan lingkaran disekitar tubuh manusia tersebut. Lingkaran tersebut direpetisi dan diilustrasikan menjadi lingkaranlingkaaran yang saling bertumpuk menghasilkan bentuk baru. Bentuk tersebut dimasukan kedalam bangunan dan digunakan untuk mendesain ruang-ruang termasuk lanskap. 
Dikarenakan tapak merupakan area dengan KDB dan KB rendah hasil autput pada bangunan ini pun berupa perpecahan massa yang dibagi menjadi 3 macam berdasarkan kebutuhannya. Desain lanskap juga diperhatikan agar pengunjung bisa menikmati suasana sekitar. Vegetasi juga diperhatikan selain untuk meredam suara yang dihasilkan dari sekitar yang dikarenakan tapak berada di pinggir jalan primer, vegetasi juga digunakan untuk tujuan memberikan kenyamanan pada pengunjung. Di daerah lanskap inilah para pengunjung bisa datang tanpa harus membayar tetapi masih bisa berkumpul dan menikmati suasana sambil bercengkrama dengan pengunjung lainnya.

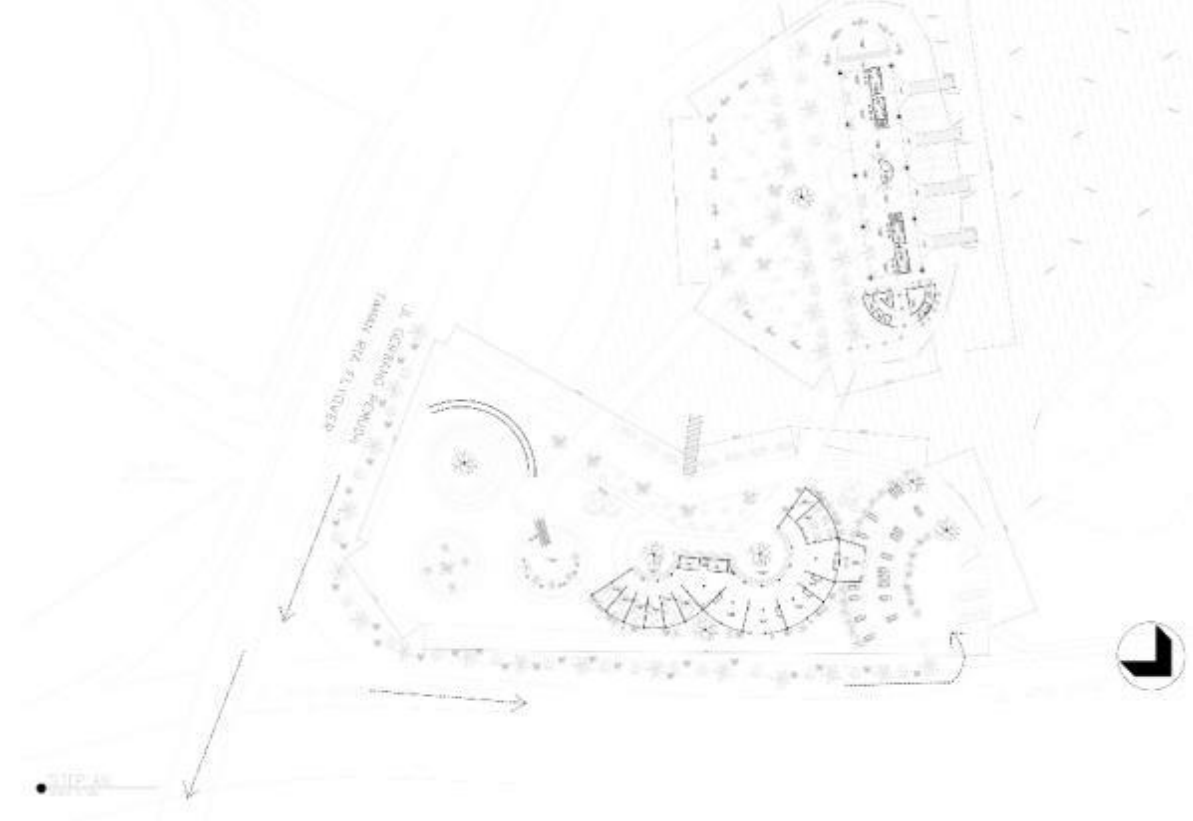

Gambar 6. Siteplan

Sumber: Penulis, 2019

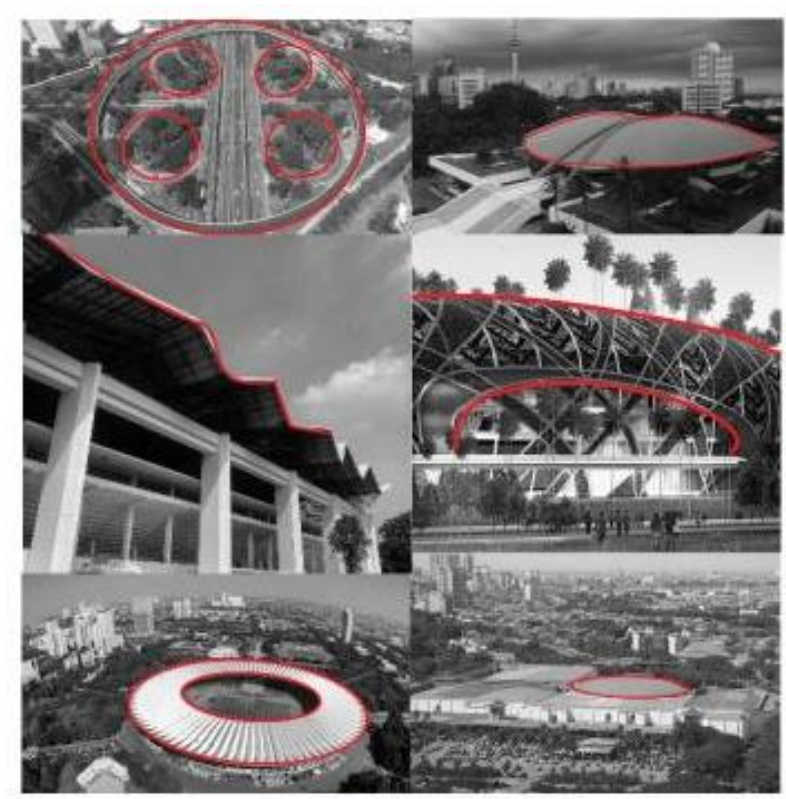

Gambar 7. Inspirasi Bangunan Sekitar Sumber: Penulis, 2019 
Bangunan di sekitar tapak memiliki aksen melingkar maupun melengkung, beberapa elemen dari bangunan tersebut dimasukan kedalam desain bangunan sebagai bentuk penghormatan terhadap tapak sekitar (kontekstual).

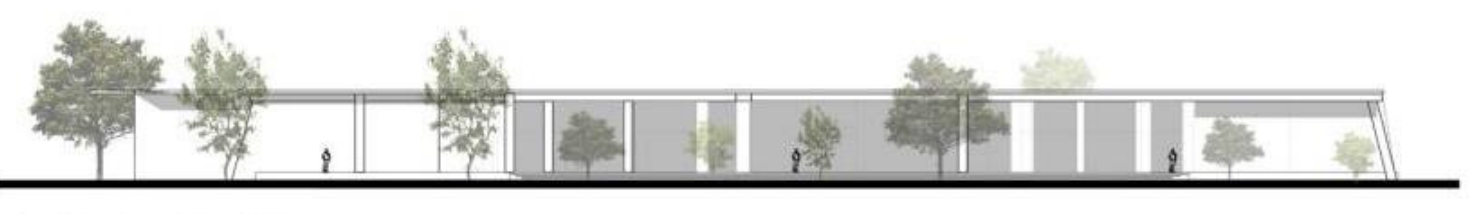

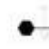

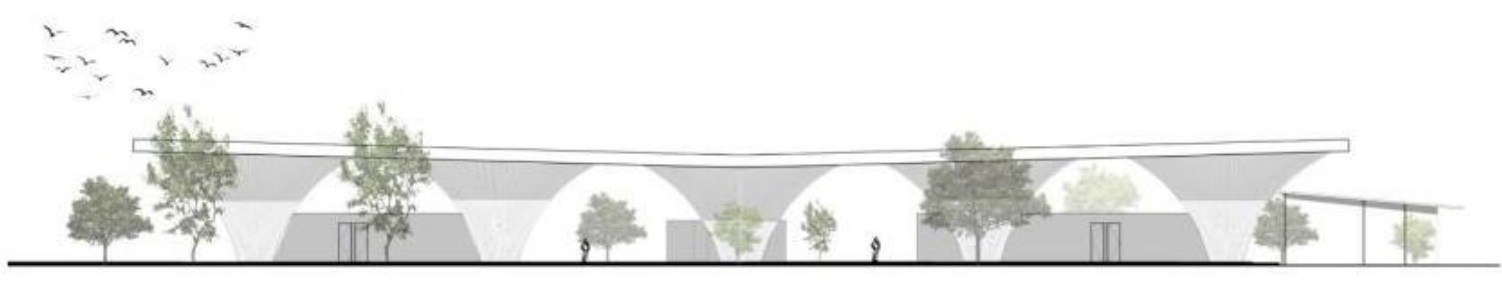

- TaMpá tivir materlake SPORT
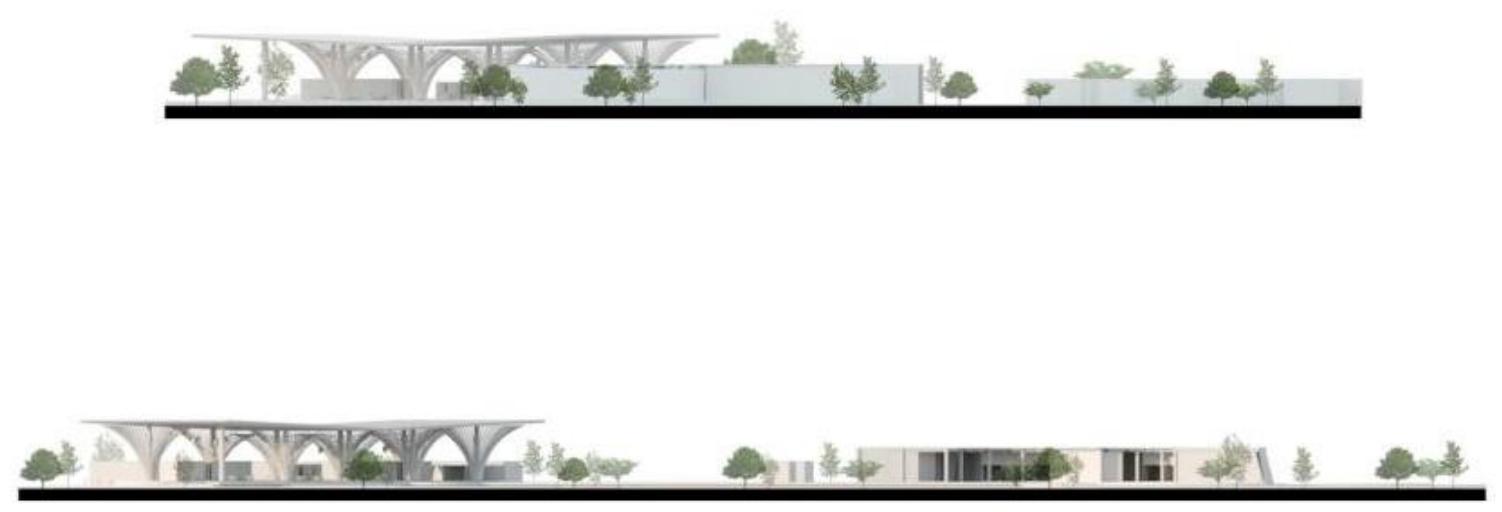

Gambar 8. Potongan

Sumber: Penulis, 2019 

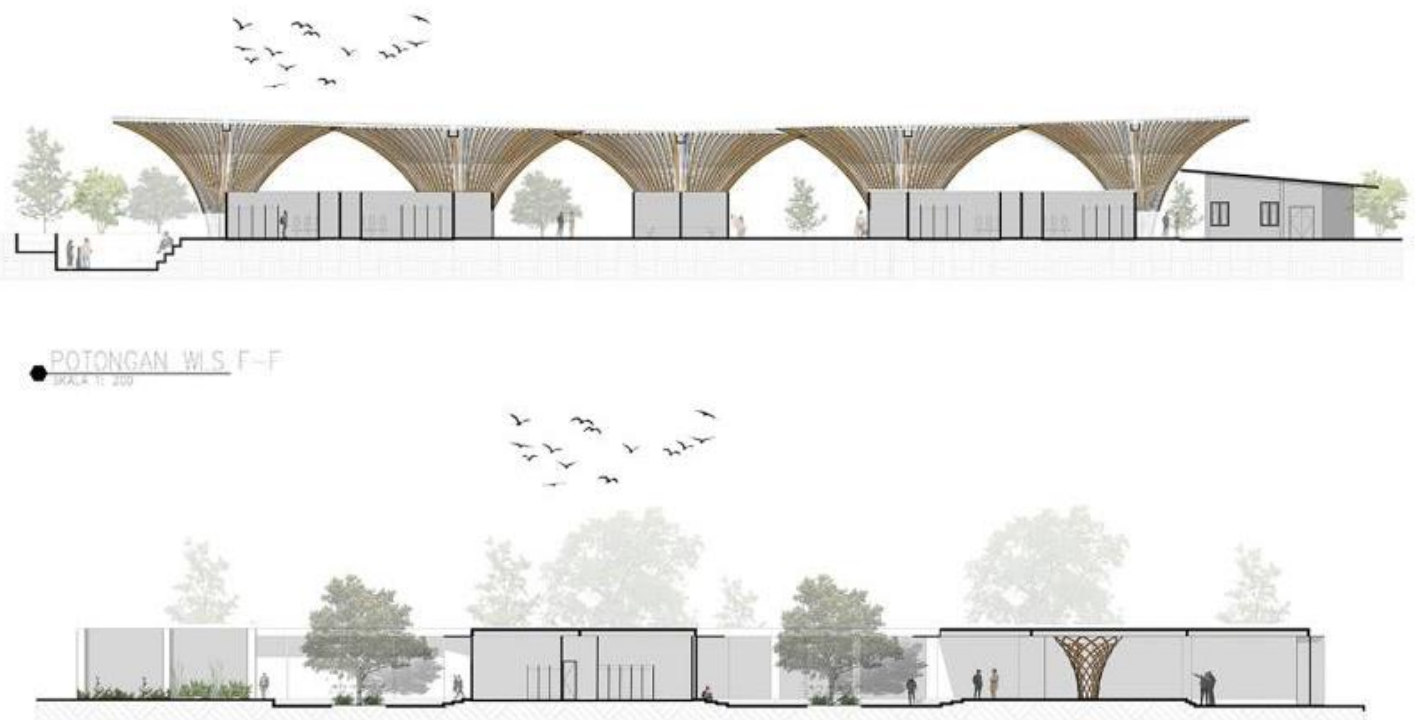

- Pot retall B-e
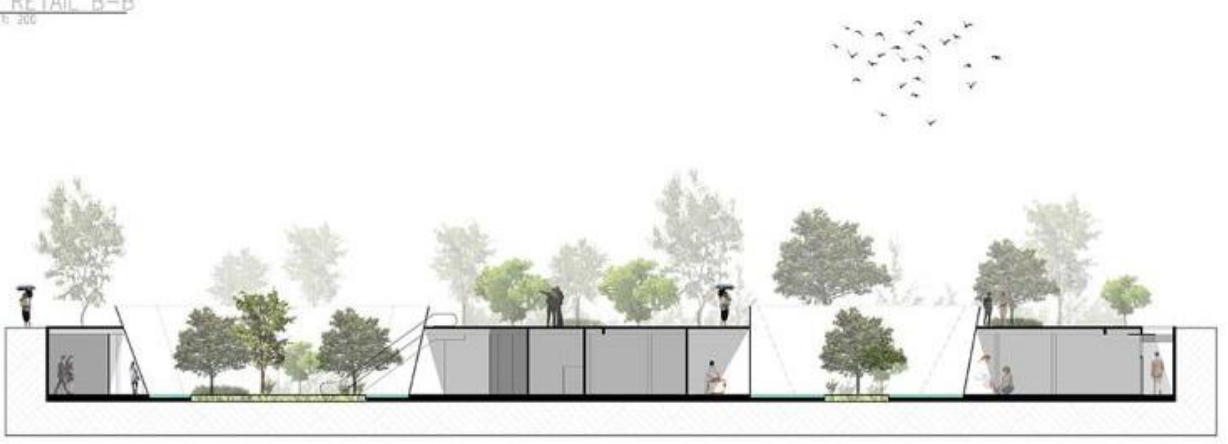

-

Gambar 9. Potongan Health and Leisure

Sumber: Penulis, 2019

\section{KESIMPULAN DAN SARAN}

Kesehatan merupakan merupakan aset berharga didalam kehidupan masyarakat. Pentingnya menjaga kesehatan sudah menjadi prioritas utama. Di Jakarta sendiri masalah kesehatan sudah bisa cukup ditekan khususnya untuk penyakit menular seperti yang sudah disinggung di atas. Penyebaran penyakit yang tidak menular bisa ditekan dan dicegah melalui tiap individu dari cara menjaga kesehatan dengan baik seperti berolahraga teratur dan menerapkan pola makan sehat. Ini merupakan 2 poin utama sebagai kunci dari jasmani dan rohani yang sehat.

Sebuah wadah kreatif yang ditunjukan untuk masyarakat agar lebih mengenal dan menyukai olahraga dengan cara berbeda yang lebih menyenangkan seperti memperkenalkan olahraga yang masih bisa dibilang asing di Indonesia khususnya di Jakarta sebagai bentuk respon terhadap masalah. Tapak yang berpusat di kawasan olahraga Jakarta menjadi pilihan utama. Dengan melihat dan mengamati kawasan GBK serta fasilitas yang sudah tersedia, sportaiment menjadi pelengkap elemen fasilitas GBK khususnya dibidang olahraga air. Lokasi yang berada di tengah kota ini juga mempermudah pencapaian masyarakat luas dari berbagai penjuru Kota Jakarta. 
Program-program yang ada didalam tapak ditunjukan sebagai respond design terhadap masalah untuk meningkatkan kecintaan serta mengajak masyarakat agar giat berolahraga serta menjawab masalah antara first place dan second place. Selain itu, area kuliner sehat berbasis makanan organic serta perhitungan kalori juga menjadi salah satu program utama. Tempat olahraga dan tempat kuliner sendiri pada dasarnya sudah menjadi third place dimana orang-orang bisa berkumpul, bercengkrama, melepas kepenatan masalah-masalah yang terjadi baik di ruang pertama maupun ruang kedua. Hal ini juga sudah sejalan dengan arti sportainment dimana sportaintment tidak hanya mengolah kesehatan tubuh namun juga mendapatkan hiburan dan pertunjukan.

\section{REFERENSI}

Alexander, C. (1979). A Pattern Language. Town. Buildings. Construction. California: Center for Environmental Structure.

Badan Pusat Statistik. (2018). Kecamatan Gelora dalam Angka, Jakarta: BPS.

Data dan Informasi Profil Kesehatan Indonesia (2018)

Lathouri, M. (2011). The City as a Project: Types, Typical, Objects and Typologies. London: AA Publications.

Moneo, R. (1978). On Typology, Oppositions, Cambridge: MIT Press.

Montgomerry, C. (2013). Happy City.Canada:Farrar

Notoatmodjo, S. (2003). Pendidikan Dan Perilaku Kesehatan. Jakarta: Rineka Cipta.

Oldenburg, R. (1997).The Great, Good Place. Cambridge: Da Capro Press

Quatremère de Quincy, A. (1832). Dictionnaire Historique de L'Architecture, Paris: Librairie d'Adrien Le Clere et cie.

Robertson, L. (2019). This Museum Believes Art Is For All, Jakarta: The Jakarta Post. 
